\title{
Variation in the extraction efficiency of estradiol and progesterone in moist and lyophilized feces of the black howler monkey (Alouatta pigra): alternative methods
}

\author{
Vianey del R. Torres-Pelayo ${ }^{1}{ }^{*}$, M. J. Rovirosa-Hernández ${ }^{1}$, F. García-Orduña ${ }^{1}$, R. D. Chavira-Ramírez ${ }^{2}$, \\ L. Boeck ${ }^{2}$, D. Canales-Espinosa ${ }^{1}$ and J. F. Rodríguez-Landa ${ }^{1}$
}

Instituto de Neuroetología, Universidad Veracruzana, Veracruz, México

${ }^{2}$ Departamento de Biología de la Reproducción, Instituto de Ciencias Médicas y Nutrición Salvador Zubirán, México City, México

\section{Edited by:}

Xiaogang Wu, Indiana

University-Purdue University

Indianapolis, USA

Reviewed by:

Sudipto Saha, Case Western Reserve University, USA

Tianshou Zhou, Sun Yat-Sen

University, China

Mingyi Wang, The Samuel Roberts

Noble Foundation, USA

*Correspondence:

Vianey del R. Torres-Pelayo,

Departamento de Biología de la

Conducta, Instituto de Neuroetología,

Universidad Veracruzana, Dr. Luis

Castelazo $s / n$, Col. Industrial Las

Ánimas, CP 91190 Xalapa, Veracruz,

México.

e-mail: torrespvr@hotmail.com
Several fecal steroid extraction techniques have been developed to measure the ovary function in different species of mammals. However, regardless of the method of extraction and the sample type chosen, it has been observed that they can yield results with different percentages of recuperation. The objective of this study was to determine whether the type of substratum, solvent and extraction method used have any influence on the extraction efficiency in the feces of Alouatta pigra (black howler monkey). For this purpose we used two methods: agitation and ebullition. With each method, we utilized moist and lyophilized feces. The validation of radioimmunoassay method was accurate and precise for quantify estradiol and progesterone in lyophilized feces of $A$. pigra. To both of which ethanol and methanol, absolute and at $80 \%$, were added, besides the hormones ${ }^{125}$-Estradiol and ${ }^{125}$ I-Progesterone. The extraction efficiency for ${ }^{125}$ I-Estradiol was from $87.72 \pm 3.97$ to $41.24 \pm 2.67 \%$, and for ${ }^{125}$ /-Progesterone from $71.15 \pm 4.24$ to $42.30 \pm 1.19 \%$ when we used the agitation method. Whereas with the ebullition method, the extraction efficiency for ${ }^{125}$ I-Estradiol ranged from $86.89 \pm 2.66$ to $71.68 \pm 3.02 \%$ and for ${ }^{125}$ I-Progesterone from $98.31 \pm 1.26$ to $85.40 \pm 1.98 \%$. Due to the differences found in these assays, which depend on the method used, the type of feces employed and the type of solvent added to them, we recommend the ebullition method and the lyophilized feces of $A$. pigra for extracting the hormones, since in moist feces there may exist variables which might interfere in the quantification of ${ }^{125} \mathrm{I}$-Estradiol and ${ }^{125} \mathrm{I}$-Progesterone.

Keywords: extraction method, estradiol, progesterone, feces, Alouatta pigra

\section{INTRODUCTION}

Fecal hormone analysis has provided a non-invasive tool for monitoring the endocrine condition in wild animals (Mateo and Cavigelli, 2005) and has been extensively employed in the field endocrinology of non-human primates (Brockman and Whitten, 1996; Ziegler et al., 1996). This contribution is important when the physiological events to be studied are infrequent or continue for long periods (Lasley and Kirkpatrick, 1991; Harper and Austad, 2000; Wasser et al., 2000; Millspaugh et al., 2001, 2002; Möstl and Palme, 2002; Touma et al., 2003). Therefore the acknowledged value of monitoring the reproductive function through the analysis of hormones in excreta has created interest in the choice of an appropriate biological sample, because the feces of diverse vertebrates contain a mixture of metabolized hormones such as progestins, estrogens, androgens, glucocorticoids, and mineral corticoids (Palme and Möstl, 1997; Hunt et al., 2004) which, in some cases, are mixed with metabolites of different polarities (Goymann, 2005; Möstl and Palme, 2005; Palme, 2005). Adlercreutz and Martin (1980) propose that the excretion rate and the metabolism of steroid hormones and their metabolites vary from one species to another, which must be considered for the procedures of steroid extraction from feces (Möstl and Palme, 2005; Palme, 2005; Ziegler and Wittwer, 2005).
Since the techniques of fecal hormone extraction have facilitated hormone analysis, it becomes necessary to concentrate the substance of interest and, at the same time, to eliminate those compounds that may interfere in said analysis (Wasser et al., 1993; Möstl and Palme, 2005), such as water, urine, and inert matter, which can mask the quantification of steroid hormones. Some research methods used for hormone extraction are based on the selection of a solvent, the application of temperature (Gao and Liu, 2005), the types and time of agitation, using moist feces (Heistermann et al., 1996; Wasser et al., 2000; Hunt and Wasser, 2003; Hunt et al., 2004; Cristóbal-Azkarate et al., 2007) nor lyophilized feces (Wasser et al., 1997, 2004; Goymann et al., 1999; Khan et al., 2002; Hunt et al., 2004) from diverse species of mammals. Also in these studies include the evaluation of free ligand activity added to the substratum and validation of the assay (Buchanan and Goldsmith, 2004; Palme et al., 2005).

In order to quantify the steroid metabolites in primate feces, has been necessary determine the efficacy of the hormone recovery to be studied in moist or lyophilized fecal samples (Risler et al., 1987; Wasser et al., 1988, 1992; Ziegler et al., 1996), and also what type of solvent can be used to improve the efficiency of hormonal recovery from feces. For the moment, there are few if any standardized techniques for evaluating the extraction efficacy in both samples for 
the same species of primates, as is the case of the species Alouatta pigra (black howler monkey).

Steroids from the moist feces of black howler monkey (A. pigra) have been extracted, and the efficacy of the extraction of steroid metabolites radio marked with tritium have been evaluated (Van Belle et al., 2009). However, due to factors which may or may not modify the measurement of efficiency of hormone extraction in feces from the species (Wasser et al., 1988; Brown et al., 1994; Ziegler et al., 1996; Terio et al., 2002; Palme, 2005), we consider that is necessary to add radio marked hormones to the fecal samples in order to measure the quantity of said tracer at the time of implementing a new method of extraction in such a way that the recovered percentage of the tracer makes it possible to evaluate the recovery efficacy in the biological sample. The objectives of this study were: (1) to determine whether the physical condition of the sample (moist or lyophilized feces) and the type of solvent may influence the extraction efficacy of the hormones ${ }^{125} \mathrm{I}-$ estradiol and ${ }^{125}$ I-progesterone added to the stratum (feces); (2) to compare the protocol for extraction in this study, agitation vs. ebullition, in order to obtain and value the percentage of increased extraction efficiency of the radio marked hormone added to moist and lyophilized feces of howler monkeys; and (3) to validate the hormonal extraction technique in the lyophilized feces of A. pigra.

\section{METHODS}

\section{STUDY SITE AND SUBJECTS}

In this study, we collected fecal samples from 16 free-living adult female black howler monkeys (A. pigra) belonging to different groups (Office No. SGPA/DGVS/04949/07). These were collected during November and December, 2007 in fragmented forest on the private property of the Alamo $\left(18^{\circ} 48^{\prime} 15.1^{\prime \prime} \mathrm{N}\right.$ and $\left.90^{\circ} 58^{\prime} 59.8^{\prime \prime} \mathrm{W}\right)$ and Calax Ranches ( $18^{\circ} 50^{\prime} 37.6^{\prime \prime} \mathrm{N}$ and $\left.91^{\circ} 18^{\prime} 26.4^{\prime \prime} \mathrm{W}\right)$ and the Tormento Natural Reserve $\left(18^{\circ} 16^{\prime} 25^{\prime \prime} \mathrm{N}\right.$ and $\left.90^{\circ} 43^{\prime} 55^{\prime \prime} \mathrm{W}\right)$, all areas belonging to Campeche, Campeche, México.

\section{FECAL SAMPLE COLLECTION}

Fecal samples were collected immediately after the first individual excretions (between 0700 and 0900 hours) and transferred into a commercial plastic container $(50 \mathrm{ml})$ with a lid. These fresh fecal samples were collected if they were clean of urine or any other pollutant (e.g., rain and rubbish). All fecal samples from different females were pooled and homogenized together, then put into a container for transport and storage in a freezer at $-20^{\circ} \mathrm{C}$ until their analysis in the Laboratory of Steroid Hormones, National Institute of Medical Sciences and Nutrition "Salvador Zubiran," Mexico D.F. All the samples were stored and transported under the same conditions.

\section{SAMPLE PREPARATION}

From the previously frozen fecal samples, 42 were defrosted gradually to room temperature and later weighed $(\sim 0.600 \mathrm{~g})$; then they were placed in a $(50 \mathrm{ml})$ tube of polypropylene previously labeled. The other frozen samples $(n=35)$ were lyophilized to dryness during 3 days in a freeze dry system (LABCONCO, Freezone 6, EQUIPAR S.A. de C.V. México) and pulverized in a mortar to remove the inert material, as well as leaves and hard seeds, as described by Heistermann et al. (1996). Each sample was thawed and weighed $(\sim 0.200 \mathrm{~g})$, then placed in a previously labeled $50-\mathrm{ml}$ polypropylene screw-top tube, which was stored at $-20^{\circ} \mathrm{C}$ until hormonal analysis.

\section{FECAL ESTRADIOL AND PROGESTERONE EXTRACTION}

For fecal estradiol and progesterone extraction we employed two methods, (1) agitation and (2) ebullition (called boiling by Wasser). We employed said methods with some modifications to the method described by Wasser et al. (1991, 2000), Palme et al. (2000), Möstl and Palme (2002), and Cristóbal-Azkarate et al. (2006) for the extraction of steroids. In both methods we used moist and dry samples, with two organic solvents at different concentrations (absolute methanol, 80\% methanol, and 80\% ethanol).

\section{AGITATION METHODS I \\ Moist feces treated with absolute methanol and added ${ }^{125}$ I-estradiol and ${ }^{125}$ I-progesterone}

Initially we used $\sim 0.600 \mathrm{~g}$ of moist homogenized fecal sample $(n=7)$, which was placed in $15-\mathrm{ml}$ polypropylene tubes. Subsequently, $4.0 \mathrm{ml}$ of absolute methanol $\left(\mathrm{CH}_{3} \mathrm{OH}\right)$ and $1 \mathrm{ml}$ of radioactive tracer ${ }^{125}$ I-Estradiol radioimmunoassay (RIA) kit (Coat-A-Count Estradiol, DPC ${ }^{\circledR}$, Diagnostic Products Corporation, Los Angeles, CA, USA) were added directly to each tube.

Other tubes containing the same amount of moist feces $(n=7)$ received $4.0 \mathrm{ml}$ of absolute methanol and $1.0 \mathrm{ml}$ of radioactive tracer ${ }^{125}$ I-Progesterone RIA kit (Coat-A-Count Progesterone, DPC ${ }^{\circledR}$, Diagnostic Products Corporation, Los Angeles, CA, USA) to determine the recovery efficiency of each hormone, estradiol and progesterone. After that, all the tubes were shaken in a Vortex (Shaker model "Vortex") for $1 \mathrm{~min}$ in order to homogenize the samples with the methanol, and then they were shaken continuously for $18 \mathrm{~h}$. After this lapse of time, they were centrifuged at $3500 \mathrm{rpm}$ at a temperature of $4^{\circ} \mathrm{C}$ for $15 \mathrm{~min}$; then the supernatant was poured into other clean tubes and these were placed in a double boiler at $75^{\circ} \mathrm{C}$ within an extraction bell until their total evaporation. Later on, the tubes were re-suspended with $3.0 \mathrm{ml}$ of buffer (standard zero calibrator, DHEA, DPC, Los Angeles, CA, USA). Once again these tubes were placed in the double boiler at $37^{\circ} \mathrm{C}$ for $30 \mathrm{~min}$ in order to homogenize the samples and were shaken for $1 \mathrm{~min}$ in the vortex. Finally, all the samples were counted in duplicate in the gamma counter for RIA (Packard ${ }^{\circledR}$ Cobra $^{\mathrm{TM}}$ II Auto-Gamma ${ }^{\circledR}$ counter, A Canberra Company, CT, USA).

\section{Moist and lyophilized feces treated with methanol and ethanol at $80 \%$ and added ${ }^{125} /$-estradiol and ${ }^{125}$ I-progesterone}

About $4.0 \mathrm{ml}$ of $80 \%$ methanol and $1 \mathrm{ml}$ of radioactive tracer ${ }^{125} \mathrm{I}$ Estradiol RIA kit were added to the tubes with moist $(\sim 0.600 \mathrm{~g}$, $n=7)$ and lyophilized ( $\sim 0.200 \mathrm{~g}, n=7)$ previously weighed feces. Other tubes containing the same amount of moist and lyophilized feces also received the addition of $4.0 \mathrm{ml}$ of $80 \%$ methanol and $1.0 \mathrm{ml}$ of radioactive tracer ${ }^{125} \mathrm{I}$-Progesterone RIA kit, in order to monitor the extraction efficiency of each hormone. We used the same procedure previously described for hormonal extraction. 


\section{EBULLITION METHODS II \\ Moist and lyophilized feces treated with absolute methanol and $80 \%$ methanol and added ${ }^{125}$ I-estradiol and ${ }^{125}$ I-progesterone}

About $4.0 \mathrm{ml}$ of $80 \%$ methanol and $1.0 \mathrm{ml}$ of radioactive tracer

${ }^{125}$ I-Estradiol RIA kit were added to the tubes containing previously weighed $(\sim 0.600 \mathrm{~g})$ moist feces $(n=7)$. Other tubes containing previously weighed $(\sim 0.200 \mathrm{~g})$ lyophilized feces $(n=7)$ received the addition of $4.0 \mathrm{ml}$ of absolute methanol and $1.0 \mathrm{ml}$ of radioactive tracer ${ }^{125}$ I-Estradiol RIA kit to determine the extraction efficiency of these tests.

To determine the extraction efficiency of progesterone, other tubes with moist $(n=7)$ and lyophilized $(n=7)$ fecal samples received the addition of $4.0 \mathrm{ml}$ of absolute methanol and $1.0 \mathrm{ml}$ of radioactive tracer ${ }^{125}$ I-Progesterone RIA kit; whereas the remaining tubes with lyophilized feces $(n=8)$ received $4.0 \mathrm{ml}$ of $80 \%$ methanol and $1.0 \mathrm{ml}$ of the same radioactive tracer. Subsequently, all capped tubes were vortexed for $3 \mathrm{~min}$ in a pulsating vortexer (agitator model "vortex") and then placed in a hot water bath at $75^{\circ} \mathrm{C}$ for $20 \mathrm{~min}$. The tubes were removed and mixed in a pulsating vortexer during $1 \mathrm{~min}$; then all were centrifuged for $15 \mathrm{~min}$ at $3500 \mathrm{rpm}$ at $4^{\circ} \mathrm{C}$. The supernatant was poured off into a clean glass tube. The tubes with sediment were re-suspended with $1.0 \mathrm{ml}$ of absolute methanol and/or $80 \%$ methanol (only for those samples that required $80 \%$ methanol), then they were centrifuged again at $3500 \mathrm{rpm}$ for $15 \mathrm{~min}$ at $4^{\circ} \mathrm{C}$. The supernatant was transferred to the tubes that already contained the first supernatant.

Subsequently, these tubes were placed in a hot water bath at $75^{\circ} \mathrm{C}$ until evaporation occurred. Later on, they were re-suspended with $3.0 \mathrm{ml}$ of buffer (albumin 4\%) and placed again in a hot water bath at $37^{\circ} \mathrm{C}$ for $30 \mathrm{~min}$, then shaken in the vortex for $1 \mathrm{~min}$. Finally, an aliquot of $200 \mu \mathrm{l}$ was obtained from each independent fecal sample and transferred to tubes which were counted in duplicate in the gamma counter for RIA to obtain the percentage of recovery by the radioactive tracer ${ }^{125} \mathrm{I}$-estradiol and ${ }^{125} \mathrm{I}$-progesterone added to each sample in the various tests in this study.

\section{ANALYTIC VALIDATION}

\section{Accuracy}

Accuracy is the degree to which the measured concentration corresponds to the true concentration of a substance. This is related in part to the specificity of the assay. We used the dose-response curve and parallelism to determine whether the hormone in the pooled fecal extracts was interacting with the antibody in a manner similar to the standard curve; the calculations were made through parallelism. This also required an analysis of the sample pool without any added standard to determine the amount of endogenous (or background) hormone present. The concentration in all of the samples was expressed in nanogram per gram for progesterone and picogram per gram for estradiol.

\section{Dose-response study}

Extracts from dried fecal samples, randomly selected, were divided into five portions. To each portion of extracted fecal samples, a known value of the standard curve of estradiol was added, while five other portions of extracted fecal sample received a standard curve of progesterone; in both cases the first extract functioned as the control. Estradiol was added in doses of 0, 150, 500, and
$1800 \mathrm{pg} / \mathrm{ml}$ in each of the tubes, and $0,5,10$, and $20 \mathrm{ng} / \mathrm{ml}$ of progesterone were added in the other tubes. Subsequently, each aliquot was analyzed as an individual sample and counted in duplicate in the gamma counter for RIA.

\section{Parallelism}

In this study we showed the parallelism of the pool samples with the standard curve. Samples to be tested should reflect the range of normal concentrations expected. To test the parallelism between fecal extracts and standard, the pooled samples were serially diluted four times $(1: 2,1: 4,1: 8,1: 16$, and $1: 32)$ by using $E_{2}$ and $\mathrm{P}_{4}$ of the standard curve provided by the RIA kit for estradiol and progesterone. Data from each of the serially diluted samples made it possible to obtain the percentage of union of the antibody $(\% \mathrm{~B} / \mathrm{TB})$ of the standard curve and the fecal extracts. Then each aliquot was analyzed as an individual sample and counted in duplicate in the gamma counter for RIA.

\section{Precision}

Precision refers to the repeatability of a measured value or the consistency of results. It is a measure of random error defined as the variation among replicate measurements of a defined sample. The precision was assessed with the intra- and inter-assay coefficients of variation and is expressed as the coefficient of variation $(\% \mathrm{CV})$. The coefficient of variation was obtained by pooling the control samples, low, medium, and high (quality controls), all samples being analyzed in duplicate.

\section{Data analysis}

The Kolmogorov-Smirnov normality test was used in order to verify the type of data distribution. Once they passed the normality test, the data were analyzed through the One-Way ANOVA test for repeated samples, and thereafter through the Tukey test $(P<0.05)$. When the normality test was not passed, they were evaluated by using the Kruskal-Wallis test. The median coefficient of variation $(\% \mathrm{CV})$ was calculated from the internal and external variation of the fecal pool. The results are expressed as the mean $\pm \mathrm{SE}$ of each variable evaluated.

\section{RESULTS}

\section{ANALYTIC VALIDATION}

Assay validation results showed that in the dose-response curve there was a correlation coefficient of $r^{2}=0.996$ (Figure 1A) for estradiol and $r^{2}=0.999$ (Figure 1B) for progesterone. The dilutions of the fecal extracts showed parallelism with those of the standard curve for estradiol and progesterone (Figures 2A,B), with no difference in their slope (value of $P>0.05$ ). This sample curve parallels the standard curve; the sample hormone is immunologically similar to the standard and can be measured proportionately. The inter-assay variation coefficient was $9.21 \%$ for estradiol and $8.97 \%$ for progesterone; whereas the intra-assay values were $8.69 \%$ for estradiol and $8.03 \%$ for progesterone. These results enable us to evaluate the accuracy and precision of the radioimmunoassay in estimating its internal deviation and in identifying the errors made during the process. The respective cross-reactivity is provided by the manufacturer. The degree of sensitivity for the estradiol and progesterone assays in the feces was detected with a counter from 
A

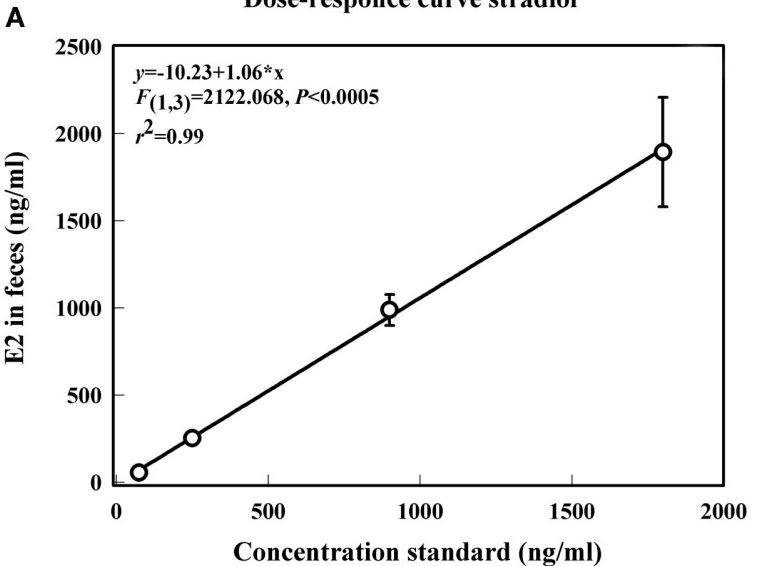

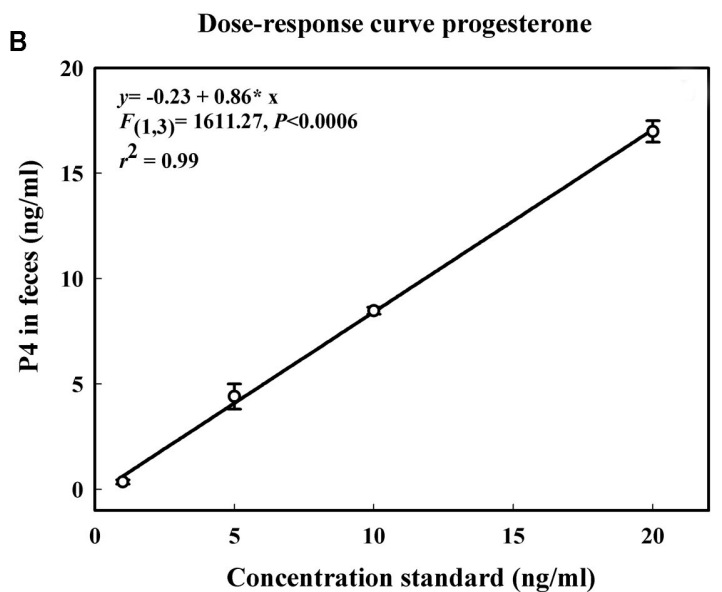

FIGURE 1 | Regression line of the standard dose-response curve for estradiol (A) and progesterone (B) in feces. Each point is the mean of five assays; vertical lines represent the SEM.

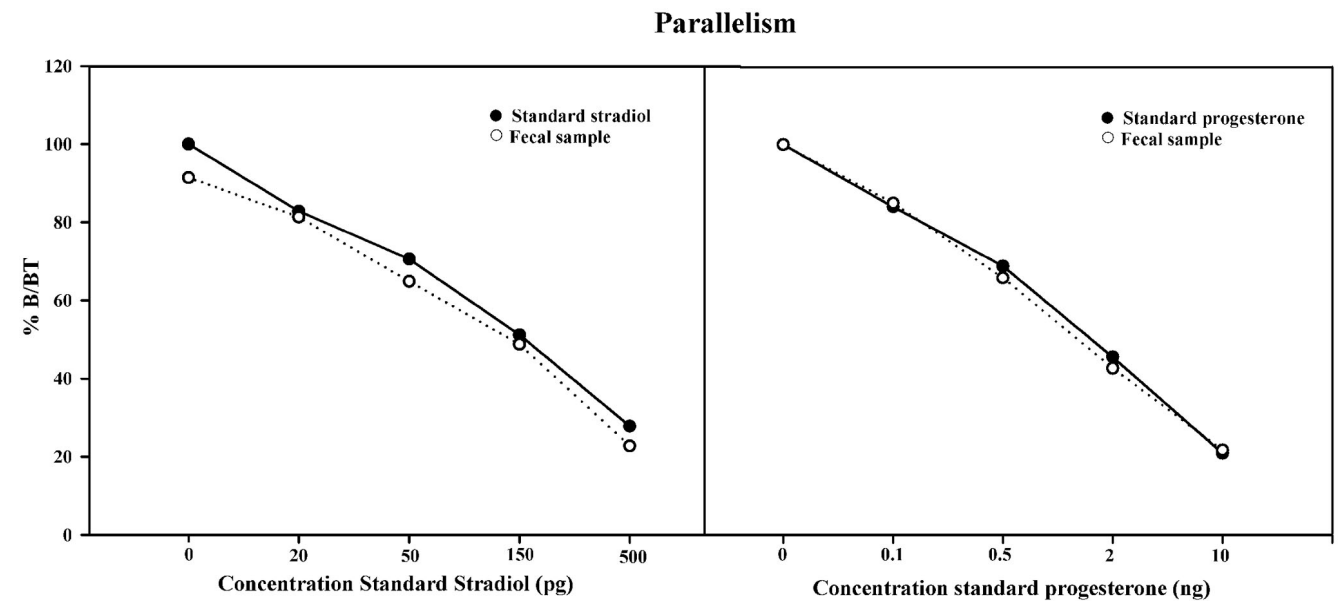

FIGURE 2 | Parallelism between a standard dilution for estradiol (A) and progesterone (B), and serial dilutions of seven different fecal extracts.

Packard ${ }^{\circledR}$ Cobra $^{\mathrm{TM}}$ II Auto-Gamma ${ }^{\circledR}$ (A Canberra Company, CT, USA), and was found to be $0.00272 \mathrm{pg} / \mathrm{ml}$ for $\mathrm{E}_{2}$ and $0.01 \mathrm{ng} / \mathrm{ml}$ for $\mathrm{P}_{4}$ (minimum concentration detectable), respectively.

\section{PERCENTAGE OF EXTRACTION EFFICIENCY}

In this study, we observed the recuperation percentage of extraction of the tracer ${ }^{125} \mathrm{I}$-Estradiol and ${ }^{125} \mathrm{I}$-Progsterone added to the moist and lyophilized feces of A. pigra, tested with two types of methods and treated with two solvents at different concentrations (see Tables 1 and 2).

\section{COMPARISON OF EXTRACTION EFFICIENCY OF TWO RADIOACTIVE TRACERS ADDED TO MOIST AND LYOPHILIZED FECES TREATED WITH TWO SOLVENTS \\ Agitation method for estradiol}

It was found that the extraction efficiency of the radioactive tracer ${ }^{125}$ I-Estradiol added to moist feces treated with ethanol at $80 \%(87.72 \pm 3.97 \%)$ showed significant differences [one-way ANOVA: $\left.F_{(2,12)}=32.514, P<0.001\right]$ when compared with that obtained from moist feces treated with absolute methanol and lyophilized feces with ethanol at $80 \%$. No significant differences $\left[F_{(1,9)}=2.658, P<0.137\right]$ were found between the extraction efficiency of the radioactive tracer ${ }^{125}$ I-Estradiol added to moist feces treated with absolute methanol and that of the same tracer added to lyophilized feces treated with ethanol at $80 \%$ (Figure 3A).

\section{Ebullition method for estradiol}

Using the ebullition method, we found significant differences $\left[F_{(1,12)}=14.220, P<0.003\right]$ between the extraction efficiency of the radioactive tracer ${ }^{125} \mathrm{I}$-Estradiol added to moist feces and to lyophilized ones, both treated with absolute methanol. The extraction efficiency with moist feces treated with absolute methanol turned out to be greater than with lyophilized feces treated with absolute methanol (Figure 3B). 
Table 1 | Shows the percentage of extraction of the tracer ${ }^{125}$ I-estradiol added in wet and lyophilized feces of Alouatta pigra tested with two types of methods.

Percentage of estradiol extraction

\begin{tabular}{|c|c|c|c|c|}
\hline \multicolumn{3}{|c|}{ Shaking methods } & \multicolumn{2}{|c|}{ Ebullition methods } \\
\hline \multicolumn{2}{|c|}{ Feces wet } & $\begin{array}{l}\text { Feces lyophilized } \\
\text { Ethanol } 80 \%\end{array}$ & $\begin{array}{l}\text { Feces wet } \\
\text { Methanol absolute }\end{array}$ & $\begin{array}{l}\text { Feces lyophilized } \\
\text { Methanol absolute }\end{array}$ \\
\hline $51.18 \pm 6.78 \%$ & $87.72 \pm 3.97 \%$ & $41.24 \pm 2.67 \%$ & $86.89 \pm 2.66 \%$ & $71.68 \pm 3.02 \%$ \\
\hline
\end{tabular}

Table 2 | Shows the percentage of extraction of the tracer ${ }^{125}$ I-progsterone added in wet and lyophilized feces of Alouatta pigra tested with two types of methods.

Percentage of progesterone extraction

\section{Shaking methods}

\begin{tabular}{|c|c|c|}
\hline \multicolumn{2}{|c|}{ Feces moist } & \multirow{2}{*}{$\begin{array}{l}\text { Feces lyophilized } \\
\text { Methanol } \mathbf{8 0} \%\end{array}$} \\
\hline Methanol absolute & Methanol $80 \%$ & \\
\hline $71.15 \pm 4.24 \%$ & $42.30 \pm 1.19 \%$ & $67.13 \pm 1.88 \%$ \\
\hline
\end{tabular}

\section{Agitation method for progesterone}

We found significant differences $\left[F_{(2,15)}=52.776, P<0.001\right]$ between the extraction efficiency of ${ }^{125}$ I-Progesterone added to moist feces treated with absolute methanol and to lyophilized feces treated with methanol at $80 \%$. However, no significant differences $\left[F_{(1,9)}=1.010, P<0.341\right]$ were noted between the extraction efficiency of ${ }^{125} \mathrm{I}$-progesterone added to moist feces treated with absolute methanol and to lyophilized feces treated with methanol at $80 \%$ (Figure 3C).

\section{Ebullition method for progesterone}

Finally, with ebullition method we found significant differences $\left[F_{(2,14)}=6.330, P<0.011\right]$ between the extraction efficiency of ${ }^{125}$ I-Progesterona added to moist feces treated with absolute methanol compared to that in lyophilized feces treated with absolute methanol and $80 \%$. When we compared the extraction efficiency of the radioactive tracer ${ }^{125}$ I-Progesterone added to lyophilized feces with absolute methanol to that obtained with lyophilized feces treated with methanol at $80 \%$, no significant differences $\left[F_{(1,11)}=0.455, P<0.514\right]$ were found between the two groups (Figure 3D).

\section{COMPARISON BETWEEN METHODS OF EXTRACTION}

We found statistically significant differences $(P<0.001$ StudentNewman-Keuls) in the mean values among the groups treated with the radioactive tracer ${ }^{125} \mathrm{I}$-estradiol and processed with two methods, agitation and ebullition. However, there were no significant differences in the percentage of extraction efficiency for ${ }^{125}$ I-estradiol between methods, when bars two and four of Figures 3A,B were compared. There were significant differences in the percentage of extraction efficiency when all the assays treated
Ebullition methods

\begin{tabular}{lll}
\hline Feces moist & \multicolumn{2}{c}{ Feces lyophilized } \\
\cline { 2 - 3 } Methanol absolute & Methanol absolute & Methanol $80 \%$ \\
\hline $98.31 \pm 1.26 \%$ & $87.82 \pm 2.84 \%$ & $85.40 \pm 1.98 \%$ \\
\hline
\end{tabular}

with the tracer ${ }^{125} \mathrm{I}$-progesterone and processed with the two methods were compared (Table 3 ).

\section{DISCUSSION \\ RIA VALIDATION}

Our results showed that fecal estradiol and progesterone from $A$. pigra can be measured with accuracy and precision in lyophilized feces with a radioimmune assay kit for commercial estradiol and progesterone. The dose-response curve in our study indicated the accuracy of the method, because nearly $100 \%$ of the steroid in the pre-processed fecal sample was recovered without chromatographic separation, that is, it allowed us to evaluate the exactness of the antibody, since both hormones showed a high correlation coefficient. This suggests that there is little interference for the substance that might bind with the antibody and produce altered results. The study in parallel for both estradiol and progesterone showed the content of the steroid extracted from the fecal samples. The dilutions of hormone contained in the feces presented a curve similar to that of standard dilutions (Figure 2), which means that the antibody immunologically recognized the structure of the standard (the radiomarked hormone), as well as that of the native hormone contained in the fecal sample. This suggests that lyophilized fecal steroids are valid as a useful tool for monitoring the reproductive status in captive A. pigra, just as they have been for other primate species (Stavisky, 1994; Stavisky et al., 1995; Palme, 2005; Touma and Palme, 2005).

The precision of the assay was generally low $(<10 \%)$ for both hormones analyzed from extracts of lyophilized feces. Similarly, other studies have reported a coefficient of variation averaging from 2.1 and $2.2 \%$ to 9.4 and $18.4 \%$ (Wasser et al., 1988, 1991; Ziegler et al., 1996; Maheshwari et al., 2010). The proper validation and standardization of these assays is only the first step 
A

Agitation method

B

Ebullition method
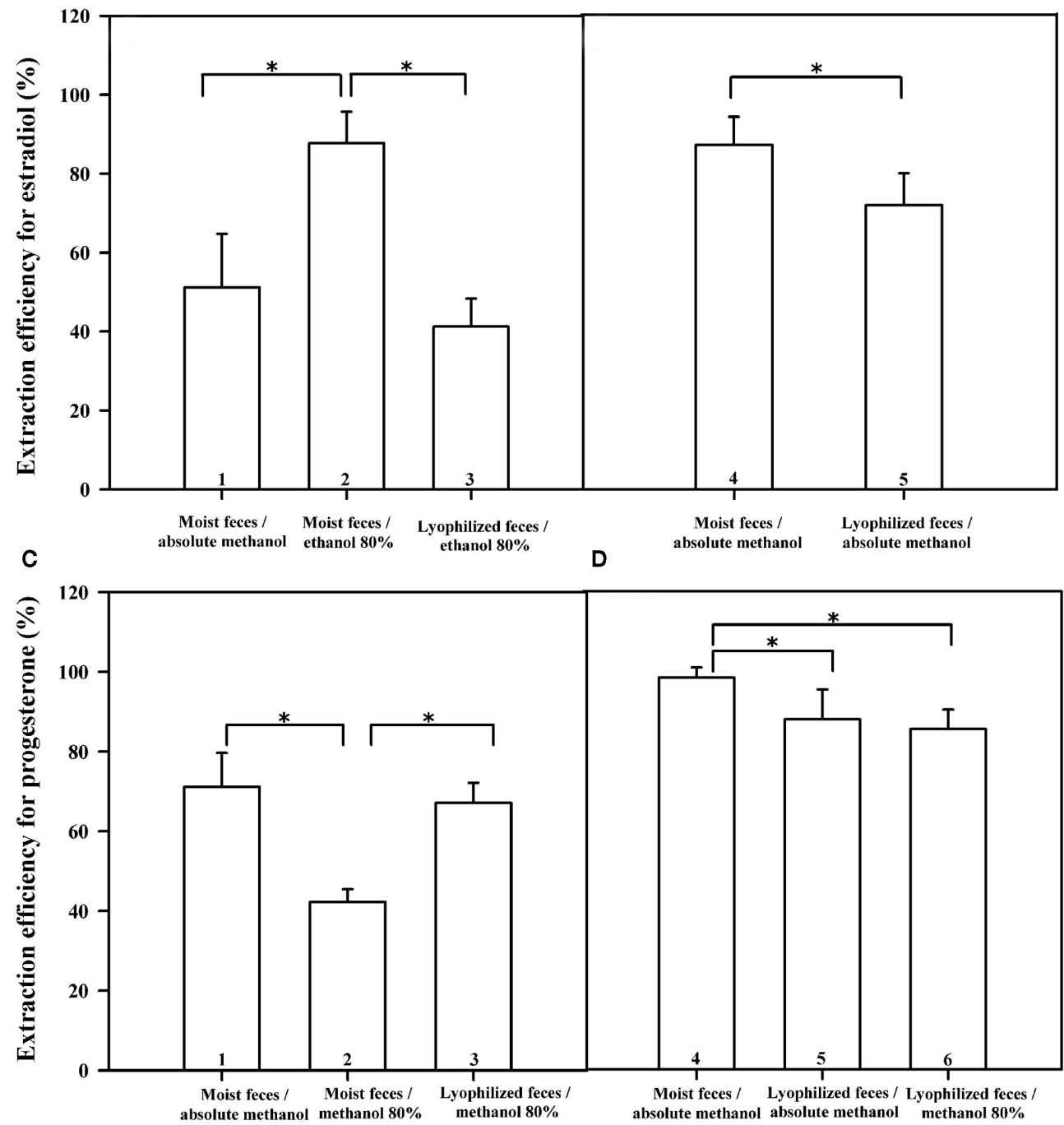

FIGURE 3 | Shows a comparison of the accuracy of extraction assessed through the quantitative recovery of exogenous ${ }^{125}$ I-Estradiol from fecal extracts with different solvents and methods. (A,C) Agitation methods, means and SE of ${ }^{125}$-Estradiol and
${ }^{125}$ I-Progesterone extracted from fecal extracts; and (B,D) Ebullition

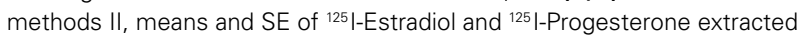
from fecal extracts (significant comparisons indicated by connecting bars on the abscissa, $\left.{ }^{*} P<0.001\right)$. toward establishing a reliable endocrine monitoring program in lyophilized feces of A. pigra. Subsequent assessment of assay quality and consistency is absolutely necessary to ensure the biological relevance of the results. We conclude that this technique of solid phase radioimmune assay was reliable and precise for evaluating hormonal levels in the lyophilized feces of A. pigra.

\section{PERCENTAGE OF EXTRACTION EFFICIENCY}

In the present study we found statistically significant differences in the percentage of extraction efficiency for ${ }^{125} \mathrm{I}$-estradiol and ${ }^{125}$ I-Progesterone added to moist and lyophilized feces from the black howler monkey A. pigra, by using two extraction methods, agitation and ebullition. Both methods proved to be efficient for recovering the added ligand and confirmed that, quantitatively, the assay detects the amount of hormone added to each fecal sample.

Generally, the extraction efficiency of the tracer ${ }^{125}$ I-Estradiol and ${ }^{125} \mathrm{I}$-Progesterone was higher in moist feces treated with different solvents than that obtained in lyophilized feces. But by eliminating the moisture and inert matter (e.g., stones or hard seeds) from the lyophilized fecal sample and processing it with the ebullition method, we found that the efficiency of extraction for both hormones was greater than that obtained with the agitation method, which indicates that the method influences the hormonal extraction efficiency. Some studies quantifying steroid hormones in mammalian feces recommend eliminating the moisture and inert matter, because they may interfere in the quantification of steroids (Martin et al., 1975; Goldin et al., 1981, 1982; Wasser et al., 
1988; Bamberg et al., 1991). However, other studies indicate that eliminating the water from the feces, for example, those of the common marmoset and the cotton-top tamarin, did not alter the profiles of estradiol concentration. The recovery of the radioactive steroid added to the feces was $>80 \%$ in both species and produced minimal effects on the quantification of steroids (Ziegler et al., 1996).

On the other hand, we found that the percentage of extraction efficiency varied when two different concentrations of organic solvent were added to the same sample type. The explanation as to why the ebullition method proved to be more effective than the agitation method for extracting hormones might be that, in the former, the application of temperature furthers the solubility of the components; in addition, the solvent is able to solvate with the radioactively marked hormone, while methanol, absolute or at $80 \%$, is better able to solvate with ${ }^{125}$ I-Progesterone. In the case of ${ }^{125}$ I-Estradiol, the use of absolute methanol favored the extraction. Many methods of fecal steroid extraction recommend the use of a vortex to optimize steroid recuperation during the extraction with methanol or ethanol (Beehner and Whitten, 2004). It seems that agitation time and temperature could influence the recuperation efficiency of the marked hormone; with mechanical agitation, the extraction of steroids from feces was from 60 to $90 \%$, similar to that reported by other researchers (Ziegler and Wittwer, 2005).

Relevant literature reports that some steroids are mainly conjugated as glucuronides or sulfates; this makes the steroids hydro-soluble and promotes changes in their polarity and retention times, thus influencing their extraction (Touma and Palme, 2005). For instance, Pappano et al. (2010) found no differences in the extraction of steroids (glucocorticoids and testosterone) from Theropithecus gelada when using methanol and acetone $(8: 2)$, or with methanol and water (9:1). However, they did find differences upon using a solution of methanol: water at 8:2. These researchers suggest that aqueous solutions extract a greater amount of polar metabolites (like glucocorticoids or conjugated metabolites); whereas organic solutions extract a lesser amount of polar metabolites (testosterone and unconjugated metabolites).

Similar studies on other mammalian quantifying hormones in the cat (Felis catus), obtained a greater extraction of $\left[{ }^{14} \mathrm{C}\right]$ Estradiol ( $90.1 \pm 0.8 \%)$ when using ethanol at $90 \%$ in comparison with ethanol at $100 \%(74.7 \pm 3.3 \%)$, a similar effect having been observed with $\left[{ }^{14} \mathrm{C}\right]$ Progesterone (87.2 \pm 1.4 vs. $56.9 \pm 0.7 \%$, respectively). This seems to indicate that the percentage of solvent used in the extraction is crucial for a better recovery of the hormone (Brown et al., 1994). To this effect, Wasser et al. (1991) point out that the extraction of hormones from lyophilized feces boiled in absolute ethanol and acetone was $88.3 \pm 0.6$ and $90.6 \pm 0.6$ for estradiol and progesterone in feces of Papio cynocephalus cynocephalus, respectively. Similarly Wasser et al. (2000) point out that the extraction of hormones from lyophilized feces boiled in ethanol at 90 or $100 \%$ is most adequate for some species (Yellow Baboon, Longtailed macaque, African elephant, Gerenuk, Scimitar-horned oryx), reporting also that hormonal extraction from moist feces/methanol or dry feces/ethanol with the ebullition method gave similar results.
Table 3 | Shows the comparison between the method of agitation and ebullition and significant differences in the percentage of extraction efficiency of all the assays treated with the tracers ${ }^{125}$ I-estradiol and 125 I-progesterone.

Method agitation vs. method ebullition

Comparisons of the extraction efficiency for ${ }^{125} \mathrm{I}$-estradiol between method agitation and ebullition (Figures $3 \mathrm{~A}$ vs. 3B)

Bar 1 vs. bar 4

$<0.001$

Bar 1 vs. bar 5

$<0.001$

Bar 2 vs. bar $4 \quad 0.877$

Bar 2 vs. bar $5 \quad 0.016$

Bar 3 vs. bar $4 \quad<0.001$

Bar 3 vs. bar $5<0.001$

Comparisons of the extraction efficiency for ${ }^{125}$ I-progesterone between method agitation and ebullition (Figures $3 \mathrm{C}$ vs. 3D)

Bar 1 vs. bar 4

$<0.001$

Bar 1 vs. bar 5

$<0.001$

Bar 1 vs. bar 6

$<0.001$

Bar 2 vs. bar 4

$<0.001$

Bar 2 vs. bar 5

$<0.001$

Bar 2 vs. bar 6

$<0.001$

Bar 3 vs. bar 4

$<0.001$

Bar 3 vs. bar 5

$<0.001$

Bar 3 vs. bar 6

$<0.001$

The numbers who have the bars indicate the type of samples treated with different solvents used in each method (see Figures $3 \boldsymbol{A}-\boldsymbol{D}$ ).

A previous study of lyophilized fecal steroid analysis for the female Javan Gibbon by Maheshwari et al. (2010) found that the average recovery of $\left[{ }^{3} \mathrm{H}\right]$-progesterone gave a mean $\pm \mathrm{SD}$ value of $78.2 \pm 6.6 \%$. Ziegler et al. (1996), on the other hand, reported high recoveries $(>80 \%)$ of tritiated steroids that were added directly to the feces before extraction to determine recoveries in two species of Callitrichids (Saguinus oedipus and Callithrix jacchus), utilizing methanol for both species. In consistency, Wasser and Hunt (2005) compared the extraction of steroids using the ebullition method with ethanol or methanol at 90 and $100 \%$; this did not alter the immune reactivity of the steroid, and the recuperation was similar ( $>85 \%$ ). Likewise, the extraction of estradiol and progesterone marked with tritium and added to moist feces of A. pigra, which were then treated with water/methanol and subjected to manual agitation, permitted a recuperation of about $91.8 \%$ for ${ }^{3} \mathrm{H}$-Estradiol and $95.0 \%$ for ${ }^{3} \mathrm{H}$-Progesterone (Van Belle et al., 2009).

In the foregoing context, we have several important observations to make. First, there is a considerable variation in the percentage of extraction efficiency of fecal $\mathrm{E}_{2}$ and $\mathrm{P}_{4}$ recovered from moist and lyophilized feces treated with different organic solvents. Second, the differences between methods suggest that the procedures, agitation, temperature, and time modify the efficiency of extraction in both samples. We conclude that the ebullition method is the more effective one for hormonal extraction, and that the type of sample, moist or lyophilized, interferes with the extraction efficiency in both of the methods employed. 


\section{ACKNOWLEDGMENTS}

We are grateful to Luis Becerra, Natalia Pérez Ariza, and Ruben Mateo Escobar for their help and support in the field, to Ariadna
E. Aguilar Duarte for her support in the laboratory, and to CONACYT for aiding me with scholarship No. 168680. We also thank Warren Haid, who corrected the manuscript.

\section{REFERENCES}

Adlercreutz, H., and Martin, F. (1980). Biliary excretion and intestinal metabolism of progesterone and estrogens in man. J. Steroid Biochem. 13, 231-244.

Bamberg, E., Möstl, E., Patzl, M., and King, G. (1991). Pregnancy diagnosis by enzyme immunoassay of estrogens in feces from nondomestic species. J. Zoo Wildl. Med. 22, 73-77.

Beehner, J. C., and Whitten, P. L. (2004). Modifications of a field method for fecal steroid analysis in baboons. Physiol. Behav. 82, 269-277.

Brockman, D. K., and Whitten, P. L. (1996). Reproduction in freeranging Propithecus verreauxi: estrus and the relationship between multiple partner matings and fertilization. Am. J. Phys. Anthropol. 100, 57-69.

Brown, J. L., Wasser, S. K., Wildt, D. E., and Graham, L. H. (1994). Comparative aspects of steroid hormone metabolism and ovarian activity in felids measured noninvasively in feces. Biol. Reprod. 51, 776-786.

Buchanan, K. L., and Goldsmith, A. R. (2004). Noninvasive endocrine data for behavioral studies: the importance of validation. Anim. Behav. 67, 183-185.

Cristóbal-Azkarate, J., Chavira, R., Boeck, L., Rodríguez-Luna, E., and Veà, J. (2007). Glucocorticoid levels in free ranging resident mantled howlers: a study of coping strategies. Am. J. Primatol. 69, 866-876.

Cristóbal-Azkarate, J., Chavira, R., Boeck, L., Rodríguez-Luna, E., and Veàl, J. (2006). Testosterone levels of free-ranging resident mantled howler monkey males in relation to the number and density of solitary males: a test of the challenge hypothesis. Horm. Behav. 29, 261-267.

Gao, M., and Liu, C. (2005). Comparison of techniques for the extraction of flavonoids from cultured cell of Saussurea medusa maxim. World J. Microbiol. Biotechnol. 21, 1461-1463.

Goldin, B. R., Adlercreutz, H., Dwyer, J. T., Swenson, L., Warram, J. H., and Gorbach, S. L. (1981). Effect of diet on excretion of estrogen in pre- and post-menopausal women. Cancer Res. 41, 3771-3773.

Goldin, B. R., Adlercreutz, H., Gorbach, S. L., Warram, J. H., Dwyer, J. T., Swenson, L., and Woods, M. N. (1982). Estrogen excretion patterns and plasma levels in vegetarian and omnivorous women. N. Eng. J. Med. 307, 1542-1547.

Goymann, W., Mostl, E., Van't Hof, T., East, M. L., and Hofer, H. (1999). Noninvasive fecal monitoring of glucocorticoids in spotted hyenas, Crocuta crocuta. Gen. Comp. Endocrinol. 114, 340-348.

Goymann, W. E. (2005). Noninvasive monitoring of hormones in bird droppings: physiological validations, sampling, extraction, sex differences, and the influence of diet on hormone metabolite levels. Ann. N. Y. Acad. Sci. 1946, 35-53.

Harper, J. M., and Austad, S. N. (2000). Fecal glucocorticoids. A noninvasive method of measuring adrenal activity in wild and captive rodents. Physiol. Biochem. Zool. 73, 12-22.

Heistermann, M., Möhle, U., Vervaecke, H., Elascker, L. V., and Hodges, J. K. (1996). Application of urinary and fecal steroid measurements for monitoring ovarian function and pregnancy in the bonobo (Pan paniscus) and evaluation of perineal swelling patterns in relation to endocrine events. Biol. Reprod. 55, 844-853.

Hunt, K., and Wasser, S. K. (2003). Effect of long-term preservation methods on fecal glucocorticoid concentrations of grizzly bear and African elephant. Physiol. Biochem. Zool. 76, 918-928.

Hunt, K. E., Trites, A. W., and Wasser, S. K. (2004). Validation of a fecal glucocorticoid assay for stellar sea lions (Eumetopias jubatus). Physiol. Behav. 80, 595-601.

Khan, M. Z., Altmann, J., Isani, S. S., and Yu, J. (2002). A matter of time: evaluating the storage of fecal samples for steroid analysis. Gen. Comp. Endocrinol. 128, 57-64.

Lasley, B. L., and Kirkpatrick, J. F. (1991). Monitoring ovarian function in captive and free-ranging wildlife by means of urinary and fecal steroids. J. Zoo Wildl. Med. 22 23-31.

Maheshwari, H., Sjahfirdi, L., Astuti, P., Purwantara, B., Sukadi, A. H., Sajuthi, D., and Widjajakusuma, R. (2010). Fecal steroid profile of female Javan Gibbons (Hylobates moloch) maintained in pairingtyped cage. Hayati 17, 43-49.

Martin, F., Peltonen, J., Laatikainen, T., Pulkkinen, M., and Adlercreutz, H. (1975). Excretion of progesterone metabolites and estradiol in feces from pregnant women during ampicillin administration. J. Steroid Biochem. 6, 1339-1346.

Mateo, J. M., and Cavigelli, S. A. (2005). A validation of extraction methods for noninvasive sampling of glucocorticoids in free-living ground squirrels. Physiol. Biochem. Zool. 78, 1069-1084.

Millspaugh, J. J., Washburn, B. E., Milanick, M. A., Beringer, L. P., and Meyer, T. M. (2002). Non-invasive techniques for stress assessment in white-tailed deer. Wildl. Soc. Bull.30, 899-907.

Millspaugh, J. J., Woods, R. J., Hunt, K. E., Raedeke, K. J., Brundige, G. C., Washburn, B. E., and Wasser, S. K. (2001). Fecal glucocorticoid assays and the physiological stress response in elk. Wildl. Soc. Bull. 29, 899-907.

Möstl, E. S., and Palme, R. (2002). Hormones as indicators of stress. Domest. Anim. Endocrinol. 23 67-74.

Möstl, E. S., and Palme, R. (2005). Measurement of corticosterone metabolites in birds' dropping: an analytical approach. Ann. N. Y. Acad. Sci. 1046, 17-34.

Palme, R. (2005). Measuring fecal steroids: guidelines for practical application. Ann. N. Y. Acad. Sci. 1046, 75-80.

Palme, R., and Möstl, E. (1997). Measurement of cortisol metabolites in feces of sheep as a parameter of cortisol concentration in blood. Int. J. Mamm. Biol. 62, 192-197.

Palme, R., Rettenbacher, S., Touma, C. El-Bahr, S. M., and Möstl, E. (2005). Stress hormones in mammals and birds: comparative aspects regarding metabolism, excretion and noninvasive measurement in fecal samples. Ann. N. Y. Acad. Sci. 1040, 162-171.

Palme, R., Robia, C., Baumgartner, W. and Möstl, E. (2000). Transport stress in cattle as reflected by an increase in fecal cortisol metabolites. Vet. Rec. 146, 108-109.

Pappano, D. J., Roberts, E. K., and Beehner, J. C. (2010). Testing extraction and storage parameters for a fecal hormone method. Am. J. Primatol. 72, 934-941.

Risler, L., Wasser, S. K., and Sackett, G. P. (1987). Measurement of excreted steroids in Macaca nemestrina. Am. J. Primatol. 12, 91-100.

Stavisky, R. C. (1994). Socioendocrinology: Noninvasive Techniques for Monitoring Reproductive Function in
Captive and Free-Ranging Primates. Ph.D., Department of Anthropology, Emory University, Atlanta.

Stavisky, R. C., Russell, E., Stallings, J. Smith, E. O., Worthman, C., and Whitten, P. L. (1995). Fecal steroid analysis of ovarian cycles in freeranging baboons. Am. J. Primatol. 36, 285-297.

Terio, K. A., Brown, J. L., Moreland, R., and Munson, L. (2002). Comparison of different drying and storage methods on quantifiable concentrations of fecal steroids in the cheetah. Zoo Biol. 21, 215-222.

Touma, C., and Palme, R. (2005). Measuring fecal glucocorticoid metabolites in mammals and birds: the importance of a biological validation. Ann. N. Y. Acad. Sci. 1046, 54-74.

Touma, C., Sacher, N., Möstl, E., and Palme, R. (2003). Effects of sex and time of day on metabolism and excretion of corticosterone in urine and feces of mice. Gen. Comp. Endocrinol. 130, 267-278.

Van Belle, S., Estrada, A., Ziegler, E. T., and Strier, K. B. (2009). Sexual behavior across ovarian cycles in wild black howler monkeys (Alouatta pigra): male mate guarding and female mate choice. Am. J. Primatol. 71, 153-164.

Wasser, S. K., Bevis, K., King, G., and Hanson, E. (1997). Noninvasive physiological measures of disturbance in the northern spotted owl. Conserv. Biol. 11, 1019-1077.

Wasser, S. K., Davenport, B., Ramage, E. R., Hunt, K. E., Parker, M., Clarke, C., and Stenhouse, G. (2004). Seat detection dogs in wildlife research and management: application to grizzly and black in the Yellowwhead Ecosystem, Alberta, Canada. Can. J. Zool. 82, 475-492.

Wasser, S. K., and Hunt, K. E. (2005). Noninvasive measures of reproductive function and disturbance in the barred owl, great horned owl, and northern spotted owl. Ann. N. Y. Acad. Sci. 1046, 109-137.

Wasser, S. K., Hunt, K. E., Brown, J. L., Cooper, K., Crockett, C. M., Bechert, U., Millspaugh, J. J., Larson, S., and Monfort, S. L (2000). A generalized fecal GC assay for use in diverse array of nondomestic mammalian and avian species. Gen. Comp. Endocrinol. 120, 260-275. 
Wasser, S. K., Monfort, S. L., and Wildt, D. E. (1991). Rapid extraction of fecal steroids for measuring reproductive cyclicity and early pregnancy in free-ranging yellow baboons (Papio cynocephalus cynocephalus). J. Reprod. Fertil. 92, 412-423.

Wasser, S. K., Risler, L., and Steiner, A. R. (1988). Excreted steroids in primate feces over the menstrual cycle and pregnancy. Biol. Reprod. 39, 862-872.

Wasser, S. K., Thomas, R., Nair, P. P., Guidry, C., Southers, J., Lucas, J., Wildt, D. E., and Monfort, S. L. (1993). Effects of dietary fiber on fecal steroid measurements in baboons (Papio cynocephalus cynocephalus). J. Reprod. Fertil. 97, 569-574.
Wasser, S. K., Thomas, R. I., Nair, P. P., and Monfort, S. L. (1992). Controlling for effects of diet on excretion of fecal progestogens. Biol. Reprod. 46(Suppl. 1), 97.

Ziegler, T. E., Scheffler, G., Wittwer, D. J., Schultz-Darken, N., Snowdon, C. T., and Abbott, D. H. (1996). Metabolism of reproductive steroids during the ovarian cycle in two species of Callitrichids, Saguinus oedipus and Callithrix jacchus, and estimation of the ovulatory period from fecal steroids. Biol. Reprod. 54, 91-99.

Ziegler, T. E., and Wittwer, D. J. (2005). Fecal steroids research in the field and laboratory: improved methods for storage, transport, processing and analysis. Am. J. Primatol. 67, 159-174.

Conflict of Interest Statement: The authors declare that the research was conducted in the absence of any commercial or financial relationships that could be construed as a potential conflict of interest.

Received: 02 October 2011; paper pending published: 23 October 2011; accepted: 23 November 2011; published online: 19 December 2011.

Citation: Torres-Pelayo VdR, RovirosaHernández MJ, García-Orduña $F$ Chavira-Ramírez RD, Boeck L, CanalesEspinosa $D$ and Rodríguez-Landa JF (2011) Variation in the extraction efficiency of estradiol and progesterone in moist and lyophilized feces of the black howler monkey (Alouatta pigra): alternative methods. Front. Physio. 2:97. doi: 10.3389/fphys.2011.00097

This article was submitted to Frontiers in Systems Biology, a specialty of Frontiers in Physiology.

Copyright (C) 2011 Torres-Pelayo, Rovirosa-Hernández, García-Orduña, Chavira-Ramírez, Boeck, CanalesEspinosa and Rodríguez-Landa. This is an open-access article distributed under the terms of the Creative Commons Attribution Non Commercial License, which permits non-commercial use, distribution, and reproduction in other forums, provided the original authors and source are credited. 